\title{
GAMPI
}

\section{IDENTIFICAÇÃO DE PONTOS CRÍTICOS NO PROCESSO DE ADAPTAÇÃO E PERSONALIZAÇÃO DE ÓRTESES E PRÓTESES: UM ESTUDO DE CASO.}

Identification of critical points on the process of adaptation and customization of orthotics and prosthetics: a case study.

MATTOZO, Tiago; Pós-Graduado em Marketing Estratégico; Universidade do Vale do Itajaí. tiagomattozo@gmail.com

BATISTA, Vilson João; Pós-Doutor; Universidade Federal de Santa Catarina. vbatista19@gmail.com

\section{Resumo}

Segundo o CENSO (2010), mais de quarenta e cinco milhões de brasileiros possuem alguma deficiência. Apesar de existirem tecnologias avançadas, a produção de órteses e próteses, de modo geral, ainda é bastante incipiente no Brasil. O problema de pesquisa deste estudo é a identificação dos pontos críticos no processo de adaptação e personalização de órteses e próteses. Para tal, foi realizado o mapeamento e descrição das etapas deste processo através de visitas técnicas e entrevista informal. Os principais pontos críticos encontram-se nas etapas Avaliação Técnica, Moldagem e Confecção. As origens dos pontos críticos despontam como possibilidades de estudos futuros.

Palavras Chave: Desenvolvimento de produtos; Órteses e Próteses; Pontos críticos.

\begin{abstract}
According to the Census (2010), more than forty-five million Brazilians have a disability. Although there are advanced technologies, the production of orthotics and prosthetics, in general, is still incipient in Brazil. The research problem of this study is the identification of critical points on the process of adaptation and customization of orthotics and prosthetics. To this end, it carried out the mapping and description of the steps of this process through technical visits and informal interview. The main critical points are located in the steps Technical Evaluation, Molding and Production. The origins of the critical points emerge as possibilities for future studies.
\end{abstract}

Keywords: Product development; Orthotics and Prosthetics; Critical Points. 


\title{
GAMPI IIral $^{15}$
}

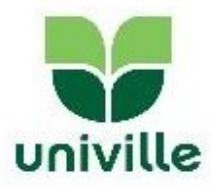

\section{Introdução}

Os dados do censo brasileiro realizado no ano de $2010^{1}$ informam que mais de quarenta e cinco milhões de brasileiros $(23,9 \%$ da população) possuem algum tipo de deficiência visual, auditiva, física/motora ou mental/intelectual - e, em muitos casos, apresentam mais de uma deficiência, ou seja, deficiência múltipla. Os indivíduos que possuem deficiência física/motora representam 7\% do total de indivíduos brasileiros. Após a deficiência visual, a deficiência física/motora é aquela que apresenta maior incidência dentre os cidadãos brasileiros, totalizando aproximadamente treze milhões e quatrocentas mil de pessoas (IBGE, 2010).

Ainda no censo 2010, as pessoas com deficiência física/motora foram identificadas também quanto ao grau de sua deficiência. Para tal, os entrevistados foram questionados em relação a sua dificuldade de mobilidade. A partir das respostas, o censo os classificou em três grupos distintos: não consegue de modo algum (mobilidade autônoma totalmente limitada); grande dificuldade (mobilidade autônoma bastante limitada); e pouca dificuldade (mobilidade autônoma pouco limitada). No primeiro grupo, foram enquadradas mais de setecentas mil pessoas, no segundo mais de três milhões e meio, e no terceiro quase nove milhões de cidadãos brasileiros.

Independentemente do grau de dificuldade, a maioria desses cidadãos, ou mesmo todos eles, utilizam algum tipo de tecnologia assistiva, especialmente órteses e/ou próteses. $\mathrm{O}$ Catálogo Nacional de Produtos de Tecnologia Assistiva, presente no site do Ministério de Ciência, Tecnologia e Inovação, esclarece as definições e diferenças de órteses e próteses:

\begin{abstract}
Órteses são dispositivos aplicados externamente para modificar as características estruturais e funcionais dos sistemas neuromuscular e esquelético. Próteses são dispositivos aplicados externamente para substituir total ou parcialmente uma parte do corpo ausente ou com alteração da estrutura. (...) Excluem-se as endopróteses, que não fazem parte da presente Norma Internacional. (CATÁLOGO NACIONAL DE PRODUTOS DE TECNOLOGIA ASSISTIVA. Disponível em $<$ http://www.assistiva.mct.gov.br>. Acesso em: 09 abr. 2014.)
\end{abstract}

Cada pessoa com deficiência física/motora apresenta características físicas extremamente particulares. Tais diferenças podem decorrer de inúmeros aspectos, tais como: o tipo da deficiência física (ex: amputação, "pé-caído", etc), a extensão da deficiência (ex: apenas nos pés, na coluna, etc), dimensões corporais singulares (ex.: comprimento do(s) membro(s), dimensões do coto, etc), característica físicas (altura e peso), dentre outros. Estas particularidades incidem diretamente sobre o processo de adaptação de órteses e próteses, demandando um produto único para cada indivíduo. Ou seja, são produtos essencialmente personalizados.

Apesar de existirem tecnologias avançadas e que permitem uma fina precisão no desenvolvimento de órteses e próteses, a produção destes dispositivos assistivos, de modo geral, ainda é bastante incipiente no Brasil. A maioria dos processos ainda é feita com

\footnotetext{
${ }^{1}$ Fonte: CARTILHA DO CENSO 2010 - PESSOAS COM DEFICIÊNCIA. Disponível em $<$ http://www.pessoacomdeficiencia.gov.br/app/publicacoes/cartilha-do-censo-2010-pessoascom-deficiencia>. Acesso em: 09 abr. 2014.
} 


\section{plural $^{\text {GI }}$}

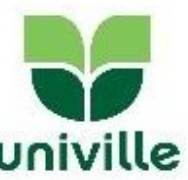

ferramentas manuais, tais como martelo, tesoura e lixa d'água. Isso se deve muito aos altos custos associados às tecnologias mais recentes. Invariavelmente, esses custos seriam repassados aos usuários, tornando esses produtos ainda mais caros e, com isso, menos acessíveis.

Portanto, o processo de adaptação de órteses/próteses, visando o conforto, a mobilidade autônoma e/ou a reabilitação de seus usuários, possivelmente apresentam pontos críticos e gargalos. Estes entraves possivelmente são frutos da contradição entre a exigência de precisão a partir de um processo produtivo majoritariamente manual.

O problema de pesquisa em questão nesse estudo é a identificação dos pontos críticos no processo de adaptação e personalização de órteses e próteses. Para tal, foi realizado o mapeamento e descrição de todas as etapas envolvidas neste processo através de um estudo de caso na empresa Ortonew.

Este estudo justifica sua validade e importância através dos números apresentados pelo Censo 2010 e descritos anteriormente. A realidade do Brasil, tanto do ponto de vista estatístico quanto tecnológico, evidencia uma preocupante carência de pesquisas científicas e projetos de produtos na área de Tecnologia Assistiva.

Em função do curto espaço de tempo disponível para a realização deste estudo, as visitas técnicas foram realizadas em apenas uma empresa. Pode-se considerar então como as principais limitações desta pesquisa o curto prazo de desenvolvimento e o estudo de caso único.

\section{Procedimentos Metodológicos}

Quanto à natureza, esta pesquisa é classificada como aplicada, pois visa levantar aspectos específicos a uma determinada empresa - a Ortonew. Quanto aos objetivos, se caracteriza por uma pesquisa descritiva, em função de buscar mapear os processos de desenvolvimento de produto e apontar seus pontos críticos. Gil (2002) afirma que pesquisas descritivas são aquelas que visam descobrir a existência de associação entre variáveis. Os procedimentos técnicos deste estudo foram: pesquisa bibliográfica e estudo de caso.

A partir disso, a pesquisa foi dividida em duas etapas distintas: levantamento teórico e pesquisa de campo. Na pesquisa bibliográfica foi realizada a busca e leitura de material teórico preliminar com o objetivo de identificar referências teóricas que apoiem os conceitos abordados no presente estudo. Na pesquisa de campo foi feita a coleta de dados através de visitas técnicas e entrevistas informais realizadas na empresa Ortonew.

\section{Fundamentação Teórica}

O corpo teórico deste estudo se orientou por produções e publicações referentes ao desenvolvimento de produtos. Dentre estas se destaca o modelo de referência apresentado por Rozenfeld et al (2006) no livro Gestão de Desenvolvimento de Produtos. Esse e outros conteúdos auxiliaram os pesquisadores no mapeamento do processo de adaptação e personalização de órteses e próteses, ocorrido na empresa-caso (Ortonew). Também foram levantados outros estudos relativos ao processo de desenvolvimento de produtos de Tecnologia Assistiva, visando abarcar material teórico relativo a este segmento específico.

\subsection{Gestão de Desenvolvimento de Produto}




\section{GAMPI
plural ${ }^{45}$}

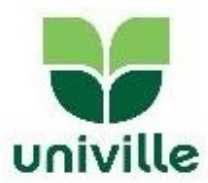

Rozenfeld et al (2006) enfatizam que o modelo de referência descrito em seu livro apresenta especificidades relativas aos desenvolvimento de bens duráveis e equipamentos. No entanto, logo em seguida os autores explicam que o modelo geral, com algumas adaptações, também pode ser adequado a outro tipo de produto.

De modo geral, desenvolver produtos consiste em um conjunto de atividades por meio das quais busca-se, a partir das necessidades do mercado e das possibilidades e restrições tecnológicas, e considerando as estratégias competitivas e de produto da empresa, chegar às especificações de projeto de um produto e de seu processo de produção (...). (ROZENFELD et al, p. 3, 2006)

Baxter (1998) afirma que a estratégia de desenvolvimento de um produto deve representar as intenções de inovação deste produto. Este mesmo autor defende que os princípios básicos de um produto surgem a partir do projeto conceitual, quando então ocorre a identificação do benefício básico, ou seja, a compreensão das necessidades dos consumidores.

Pahl et al (2005) consideram imprescindível o esclarecimento do problema e a elaboração da lista de requisitos, quando então são elencadas as necessidades dos usuários.

Segundo Benedetto (2011):

Choi e Sprigle (2011), juntamente com Cook e Hussey (2008), concordam que é conveniente envolver o usuário no início do processo de projeto para ajudar a identificar as necessidades e os potenciais problemas. Além disso, Cook e Hussey (2008) sugerem que os consumidores estejam localizados no centro de atenção do processo e, ademais, salientam que os mesmos podem ser envolvidos em todas as fases de fabricação. (BENEDETTO, 2011, p. 90)

Como se pode perceber, não são poucos os autores que reforçam a importância da observação, compreensão e foco nas reais necessidades dos usuários durante $o$ desenvolvimento de um produto. Tal pensamento ganha ainda mais força quando se tratam de produtos de Tecnologia Assistiva (TA), visto que estes são direcionados à pessoas com necessidades particulares e, em muitos casos, exigências individuais. Portanto, se pode afirmar que o desenvolvimento de produtos de TA demanda processos precisos e bem executados. Uma órtese/prótese eficaz e eficiente precisa ser funcional e confortável segundo diversas perspectivas (conforto ergonômico, conforto psicossocial, etc). Nota-se então que, para a obtenção de uma órtese e/ou prótese satisfatória, é fundamental que as tarefas envolvidas no processo de adaptação e personalização sejam precisas e, preferencialmente, livres de entraves.

\subsection{Desenvolvimento de TA}

Benedetto (2011) indica alguns estudos que contribuem para a compreensão dos requisitos do processo de desenvolvimento de produtos de TA.

"De acordo com estudos de Andrich (2001), verifica-se que o usuário deve ser o protagonista na escolha de seu auxílio, a fim de melhorar a sua autonomia, sendo imprescindível capacitar o usuário através da tecnologia assistiva." (Benedetto, 2011, p. 50)

Seguindo na mesma linha de raciocínio, Benedetto (2011) descreve um documento produzido pela EUSTAT (Empowering Users Through Assistive Technology - Capacitando Usuários Através de Tecnologia Assistiva), comissão europeia formada por cinco países 


\section{GAMPI
plural' 15}

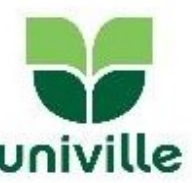

(Itália, Dinamarca, França, Bélgica e Portugal) e destinada a produzir materiais educacionais para pessoas deficientes, membros da família e cuidadores.

De acordo com o documento, a identificação de necessidades é frequentemente o ponto fraco de vários estudos e, para ultrapassar este problema, usam-se pressupostos simplistas. (...) Para assegurar-se de que esta identificação seja feita de forma adequada em domínios relevantes (como estilo de vida, produtos e serviços) deve ser encontrada uma abordagem consistente e métodos mais eficazes devem ser projetados. (Benedetto, 2011, p. 50)

Para Carvalho, Okomura e Canciglieri Junior (2010) a criação e a elaboração de dispositivos de tecnologia assistiva demandam envolvimento e interação de profissionais de diversas áreas de conhecimento, juntamente com o fornecedor e principalmente com o usuário final. Ou seja, para os autores, é necessário que o desenvolvimento de produtos de TA seja fruto de um processo interdisciplinar e, mais do que isso, reforçam ainda mais a relevância da participação do usuário neste processo.

Apesar de compreender a importância da personalização dos produtos de TA, Beretta (2011) pondera quanto a certas barreiras socioeconômicas, tais como custo e prazo de desenvolvimento.

\footnotetext{
Outro problema recorrente que este tipo de projeto enfrenta é a demora na entrega do produto final, um problema que está relacionado com a tecnologia ou a falta dela. Profissionais da saúde usam um método de "tentativa e erro" para encontrar um equipamento apropriado ou modificar um equipamento existente. Para Hobson e Crane (2001), este é um processo de alto custo e não possui estruturas de suporte fortes. Trefler e Schmeler (2001) afirmam que a entrega de um serviço consiste na tecnologia que está disponível (...) (BERETTA, 2011, p. 45)
}

Algumas premissas ficam então evidentes, tanto no desenvolvimento de bens de consumo quanto em produtos de TA. A principal delas certamente é o envolvimento dos usuários no processo de desenvolvimento. No caso dos produtos voltados às pessoas com deficiência, o foco nas reais necessidades dos usuários exige uma acurácia ainda mais criteriosa, dada às particularidades de cada indivíduo. Portanto, a seguir, o presente estudo apresentará o mapeamento dos processos de adaptação e personalização de órteses e próteses, visando identificar possíveis pontos críticos no processo de personalização.

\section{Desenvolvimento - Estudo de Caso: Ortonew}

Esta pesquisa relata um estudo de caso, por caso único, onde foram levantados dados e informações referentes à empresa Ortonew. Através de visitas técnicas e entrevistas informais com o diretor da empresa, Sr. Carlos Vieira, foi possível mapear todas as etapas envolvidas na adaptação e personalização de órteses e próteses, a fim de identificar os pontos críticos desta atividade. Por ser um estudo de caso, é importante ressaltar que os resultados aqui relatados não devem ser generalizados ou estendidos a outras empresas, ainda que pertençam ao mesmo segmento. Contudo, segundo os relatos de funcionários da Ortonew e também do diretor, de modo geral, os processos realizados na empresa são bastante similares aos realizados por outras instituições/empresas (ex.: AACD - Associação de Assistência à Criança Deficiente). 


\section{GAMPI}

Veja a Figura 1 e entenda o fluxo dos processos de adaptação e personalização de órteses e próteses realizados na Ortonew.

Figura 1 - Fluxograma dos processos de adaptação e personalização de órteses e próteses da empresa Ortonew.

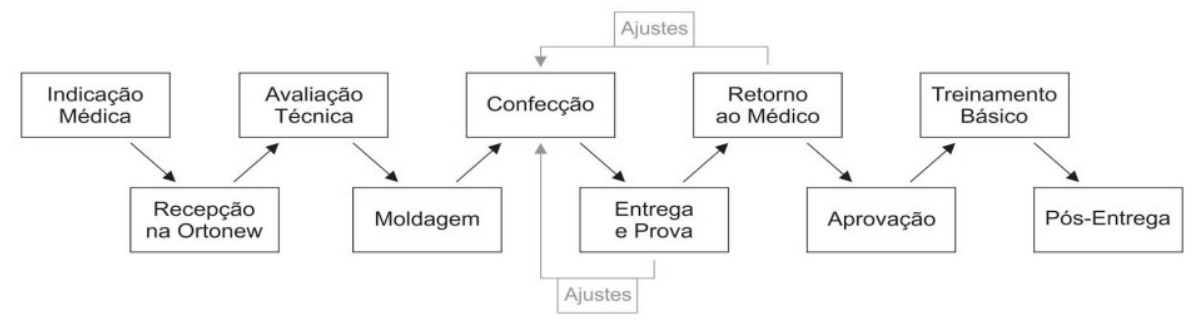

Fonte: Os autores (2014).

No Quadro 1 estão descritas todas as etapas e tarefas realizadas no processo de adaptação e personalização de órteses e próteses (expostas na Figura 1), desde a prescrição do produto assistivo até a completa adaptação do usuário ao equipamento.

Quadro 1 - Etapas e tarefas do processo de adaptação e personalização de órteses e próteses.

\begin{tabular}{|c|c|}
\hline Etapas & Tarefas \\
\hline $1^{\mathrm{a}}$ Indicação Clínica & $\begin{array}{l}\text { - Avaliação médica. } \\
\text { - Obtenção de prescrição médica (que também pode ser advinda de } \\
\text { fisioterapeuta). }\end{array}$ \\
\hline $2^{\mathrm{a}}$ Recepção na Ortonew & $\begin{array}{l}\text { - Cadastramento do paciente. } \\
\text { - Ficha/Prontuário preenchido manualmente (para pacientes em } \\
\text { atendimento particular). } \\
\text { - Ficha/Prontuário digital (para pacientes do SUS). } \\
\text { - Descrição do caso. } \\
\text { - Encaminhamento ao profissional técnico que realizará a avaliação } \\
\text { técnica. }\end{array}$ \\
\hline $3^{a}$ Avaliação Técnica & $\begin{array}{l}\text { - Avaliação do caso. } \\
\text { - Medições corpóreas do paciente. } \\
\text { - Documentação e registro das medidas corpóreas do paciente. } \\
\text { - Contato telefônico com o médico/fisioterapeuta caso surja alguma } \\
\text { dúvida e/ou discordância. }\end{array}$ \\
\hline $4^{\mathrm{a}}$ Moldagem & $\begin{array}{l}\text { - Conformação de um molde com o formato da parte do corpo a ser } \\
\text { assistida pela órtese/prótese. } \\
\text { - Aplicação de gesso. } \\
\text { - Secagem do gesso. } \\
\text { - Extração do molde do corpo do paciente. }\end{array}$ \\
\hline 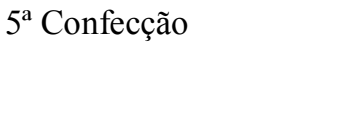 & $\begin{array}{l}\text { - Adaptação e personalização da órtese/prótese a partir do molde. } \\
\text { - Conformação da interface entre produto assistivo (órtese ou prótese) e } \\
\text { usuário com o uso de chapas de polipropileno. }\end{array}$ \\
\hline
\end{tabular}




\begin{tabular}{|c|c|}
\hline & $\begin{array}{l}\text { - Adição de elementos de acabamento (E.V.A.; tira de fixação, interface } \\
\text { de silicone e regulagem; etc). }\end{array}$ \\
\hline $6^{a}$ Entrega e Prova & $\begin{array}{l}\text { - Entrega da órtese/prótese ao paciente. } \\
\text { - Testes de encaixe (funcionalidade e conforto). } \\
\text { - Se necessário, retorno à oficina para ajustes (pode ocorrer mais de uma } \\
\text { vez). }\end{array}$ \\
\hline $7^{\mathrm{a}}$ Retorno ao Médico & $\begin{array}{l}\text { - Retorno do paciente ao médico/fisioterapeuta para verificação da } \\
\text { órtese/prótese. } \\
\text { - Se necessário, podem surgir novos ajustes a partir da avaliação do } \\
\text { médico/fisioterapeuta. }\end{array}$ \\
\hline $8^{a}$ Aprovação & $\begin{array}{l}\text { - Aprovação da órtese/prótese por parte do médico/fisioterapeuta, do } \\
\text { técnico desenvolvedor da órtese/prótese e também do usuário. }\end{array}$ \\
\hline $9^{a}$ Treinamento Básico & $\begin{array}{l}\text { - Ainda na Ortonew é feito um acompanhamento de uso, para que o } \\
\text { usuário inicie sua adaptação à órtese/prótese (ex.: adaptação da marcha, } \\
\text { para os casos de órtese/prótese de membros inferiores). }\end{array}$ \\
\hline $10^{\mathrm{a}}$ Pós-entrega & $\begin{array}{l}\text { - Caso o cliente não relate quadro de desconforto ou dor nos primeiros } 15 \\
\text { dias de uso da órtese/prótese, a Ortonew entende que o produto ficou bem } \\
\text { adaptado ao usuário. } \\
\text { - Sugere-se então a busca por um Terapeuta Ocupacional para o auxílio } \\
\text { ao treinamento de outras atividades. }\end{array}$ \\
\hline
\end{tabular}

Fonte: Os autores (2014).

Durante a entrevista para levantamento e registro das etapas e tarefas, o próprio diretor da empresa apontou as etapas mais críticas do processo. Segundo ele, os pontos críticos encontram-se nas etapas "Avaliação Técnica", "Moldagem" e "Confecção".

Na etapa "Avaliação Técnica", o entrevistado frisou a relevância da tarefa de medição corpórea do paciente. Qualquer medida mal aferida pode se desdobrar em retrabalho e problemas futuros, pois possivelmente irá ocasionar uma interface imperfeita entre a órtese/prótese e seu respectivo usuário. $\mathrm{O}$ entrevistado também mencionou que, mesmo quando bem feita, ainda assim podem surgir situações de dor ou desconforto no usuário da órtese/prótese. As variações humanas, de paciente para paciente, tanto físicas quanto neurológicas, podem levar a esses quadros adversos. O entrevistado exemplificou uma situação destas citando que determinado usuário pode contar com uma órtese/prótese bem adequada às suas medidas corpóreas, contudo o mesmo pode ter uma sensibilidade mais apurada no membro assistido (ou amputado), causando-lhe dor durante o uso da órtese/prótese.

O entrevistado também apontou dificuldades na etapa "Moldagem". Segundo ele, eventualmente ocorrem casos em que, entre a data da conformação do molde e a momento de prova da órtese/prótese, o usuário ganhe ou perca peso, ou seja, altere sua dimensão e composição corporal. Nestes casos, também é necessária a realização de ajustes, visto que ocorrem alterações nos encaixes das órteses/próteses.

Em relação à etapa "Confecção", o entrevistado relatou que o tempo de entrega de próteses ainda é um gargalo de produção e explicou de forma bastante simples o que acontece 


\section{GAMPI
plural' 15}

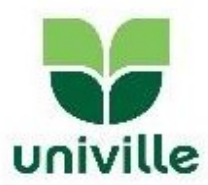

nessa situação. Por exemplo, quando um paciente amputado dá entrada na Ortonew, durante a etapa de "Avaliação Técnica" são especificados os detalhes da prótese, tais como: tamanho, cor da pele, etc. Só então, após ter estas informações, é emitido o pedido de compra da prótese e sua entrega demora cerca de quarenta dias, pois o fornecedor envia o produto a partir da Alemanha (empresa Otto Bock).

Outro ponto crítico em relação a "Confecção" reside no fato de o processo todo ser ainda majoritariamente manual. Ao observar o posto de trabalho da oficina, rapidamente percebe-se a semelhança com uma marcenaria (ou qualquer outro espaço similar a uma oficina). Este processo manual repercute em um trabalho mais lento, demandando um prazo maior para a entrega final da órtese/prótese. Buscando minimizar essa questão, o diretor da empresa informou que planeja a compra de um equipamento que realiza cortes precisos através de laser. Este equipamento possibilitará uma maior precisão nos processos de corte e também reduzirá o tempo de execução do trabalho, até então realizado de forma manual.

A partir das informações obtidas pela entrevista podem-se apontar as origens dos pontos críticos levantados, sendo estas possíveis objetos de outros estudos e aprofundamentos futuros. Cada um dos pontos críticos levantados pode ser atribuído a um determinado fato. Observe o Quadro 2 que descreve de forma objetiva a origem de cada um dos pontos críticos mencionados.

Quadro 2 - Etapas, Pontos Críticos e Origem dos Pontos Críticos do processo de adaptação e personalização de órteses e próteses.

\begin{tabular}{|l|l|}
\hline Etapa / Ponto crítico & Origem do ponto crítico \\
\hline $\begin{array}{l}\text { Avaliação Técnica / Medição } \\
\text { corpórea do usuário }\end{array}$ & $\begin{array}{l}\text { O processo de medição é realizado de forma manual, com instrumentos de } \\
\text { precisão relativa (fita métrica, paquímetro, etc). }\end{array}$ \\
\hline $\begin{array}{l}\text { Moldagem / Molde discrepante } \\
\text { com a realidade física do } \\
\text { usuário. }\end{array}$ & $\begin{array}{l}\text { A alteração corporal do usuário entre as etapas de moldagem e prova (ganho } \\
\text { ou perda de peso) é algo pouco comum, mas controlável apenas pelo próprio } \\
\text { usuário. }\end{array}$ \\
\hline $\begin{array}{l}\text { Confecção / Demora na } \\
\text { entrega das próteses }\end{array}$ & $\begin{array}{l}\text { O melhor fornecedor encontra-se na Alemanha e não há como efetuar o } \\
\text { pedido da prótese sem conhecer as características de cada indivíduo, tais: } \\
\text { tamanho e cor da pele. }\end{array}$ \\
\hline $\begin{array}{l}\text { Confecção / Demora na } \\
\text { entrega final das próteses. }\end{array}$ & $\begin{array}{l}\text { As tarefas manuais dos processos de adaptação torna todo processo mais } \\
\text { lento e demorado. }\end{array}$ \\
\hline
\end{tabular}

Fonte: Os autores (2014).

\section{Conclusão}

Tanto pelas referências teóricas quanto pelo caso estudado, percebe-se que o tema levantado neste estudo apresenta-se como um rico e pouco explorado campo de pesquisa e desenvolvimento. Ao realizar este trabalho, os pesquisadores se depararam com uma questão social urgente, visto que o Brasil conta com milhões de cidadãos com deficiência. Estas pessoas, na sua grande maioria, dependem de órteses/próteses que são desenvolvidas a partir de processos ainda pouco evoluídos tecnologicamente. Portanto, a problemática levantada neste estudo expõe uma realidade que urge por pesquisas que elevem o país a uma condição tecnológica mais coerente com o tamanho do problema. Evidentemente, por se tratar de um 


\section{glural| $^{\text {GA }}$}

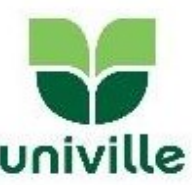

estudo de curta duração, o problema de pesquisa, apesar de real, pôde ser avaliado apenas a uma empresa. Em estudos futuros, visando um aprofundamento no problema, sugere-se a incorporação de outras técnicas de pesquisa, tais como: registro fotográfico detalhado do processo; entrevistas com usuários; visitas técnicas em outras instituições e/ou empresas; etc.

Quanto à sua contribuição científica, a presente pesquisa adiciona mais um pequeno esforço na expansão das fronteiras dos conhecimentos relativos às Tecnologias Assistivas. No campo social, a contribuição que se considera mais relevante é a ênfase na observação criteriosa das reais necessidades dos usuários de órteses/próteses. Toda comunidade envolvida em pesquisa e desenvolvimento de TA precisa estar atenta à importância de um ampliar o desenvolvimento participativo e multidisciplinar. É imprescindível o envolvimento de profissionais com competências diversas, dentre os quais os designers, e, principalmente, os próprios usuários. Com a potencialização dos esforços científicos e sociais, certamente o Brasil alcançará significativos avanços tecnológicos em relação às Tecnologias Assistivas. Neste cenário, o design possui oportunidades de pesquisa e projeto bastante promissoras, seja no aprimoramento dos processos de gestão, quanto na melhoria dos produtos em si.

Este estudo contribui com uma pequena parcela de TA (órteses e próteses), porém, dado o baixo volume de produções acadêmicas envolvendo o tema proposto, mesmo sendo restrita, esta pesquisa pode gerar estudos futuros que ampliem a profundidade dos conhecimentos relativos ao assunto tratado no presente estudo.

\section{Referências}

BAXTER, M. Projeto de produto: guia prático para o design de novos produtos / Mike Baxter; tradução Itiro Iida. - 2.ed.rev. - São Paulo: Edgard Blücher, 1998.

BENEDETTO, I. L. C. Contribuições Metodológicas para o Desenvolvimento de Produtos em Tecnologia Assistiva. 2011. 157 f. Dissertação (Mestrado) - Curso de Pósgraduação em Design, Departamento de Escola de Engenharia, Universidade Federal do Rio Grande do Sul, Porto Alegre, 2011. Disponível em: <http:/hdl.handle.net/10183/36042>. Acesso em: 5 set. 2014.

BERETTA, E. M. Tecnologia Assistiva: personalização em massa através do design e fabricação de assentos customizados para cadeiras de rodas. $2011.138 \mathrm{f}$. Dissertação (Mestrado) - Curso de Pós-graduação em Design, Departamento de Escola de Engenharia, Universidade Federal do Rio Grande do Sul, Porto Alegre, 2011. Disponível em: $<$ http://hdl.handle.net/10183/36349>. Acesso em: 05 set. 2014.

CARTILHA DO CENSO 2010 - PESSOAS COM DEFICIÊNCIA. Disponível em $<$ http://www.pessoacomdeficiencia.gov.br/app/publicacoes/cartilha-do-censo-2010-pessoascom-deficiencia>. Acesso em: 09 abr. 2014.

CARVALHO, C. E. B. de; OKUMURA, M. L. M.; CANCIGLIERI JUNIOR, O. A engenharia simultânea aplicada ao processo de desenvolvimento de produtos especiais. 2010.

Disponível em: $<$ http://www.abepro.org.br/biblioteca/enegep2010_tn_sto_117_767_17456.pdf > . Acesso em: 5 set. 2014. 


\section{GAMPI
plural ${ }^{15}$}

CATÁlOGO NACIONAL DE PRODUTOS DE TECNOLOGIA ASSISTIVA. Disponível em <http://www.assistiva.mct.gov.br>. Acesso em: 09 abr. 2014.

CHOI, Y. M.; SPRIGLE, S.H. Approaches for Evaluating the Usability of Assistive Technology Products Prototypes. Assistive Technology, n. 23. p. 36-41. RESNA, Georgia, USA, 2011.

COOK, A. M.; POLGAR, J. M. Cook \& Hussey's Assistive Technologies: Principles and Practice. Third Edition, Mosby Elsevier, Philadelphia, USA, 2008.

HOBSON, D.; CRANE, B. Wheelchair Seating Comfort. In Wheelchair Seating. Org. BRUBAKER, Clifford E.; BRIENZA, David M. Wheelchair Seating: A State-of-theScience Conference, Pittsburgh, Pennsylvania, 2001.

GIL, A. C. Como elaborar projetos de pesquisa. 4. ed. São Paulo: Ed. Atlas, 2002.

PAHL, G. et al. Projeto na engenharia: fundamentos do desenvolvimento eficaz de produtos, métodos e aplicações. São Paulo: Edgard Blucher, 2005. 411 p.

ROZENFELD, H.; FORCELLINI, F.; AMARAL, D.; TOLEDO, J.; SILVA, S.; ALLIPRANDINI, D.; SCALICE, R. Gestão de Desenvolvimento de Produtos: uma referência para melhoria do processo. Saraiva: São Paulo, 2006.

TREFLER, E.; SCHMELER, M. State of the science white paper on seating for postural control. In Wheelchair Seating. Org. BRUBAKER, CLIFFORD E.; BRIENZA, David M. Wheelchair Seating: A State-of-the-Science Conference, Pittsburgh, Pennsylvania, 2001. 